\title{
Impairment of pyridoxal phosphate dependent metabolic reactions in a child with subacute necrotizing encephalopathy
}

\author{
M. S. EBADI, ${ }^{2}$ R. BOSTAD,$^{3}$ AND R. J. PELlEGRINO \\ From the Departments of Pharmacology and Pediatrics, University of Missouri School of Medicine, U.S.A.
}

Infantile subacute necrotizing encephalopathy (ISNE), which has been described by Leigh (1951), is a disorder which shows an excessive autosomal inheritance pattern and is considered to be the result of an inborn error of metabolism (Richter, 1957). Among the possible biochemical abnormalities, thiamine deficiency (Leigh, 1951; 'Richter, 1957; Feigin and Woolf, 1954); impairments in thiamine utilization (Greenhouse and Schneck, 1968); chronic lactic acidosis (Namiki, 1965); elevated pyruvate level (Worsley, Brookfield, Elwood, Noble, and Taylor, 1965); and the presence of endogenously produced 'toxin' (Crome, 1964) have been reported. In this paper subnormalities in the activity of the enzymes decarboxylating 5-hydroxytryptophan, glutamic acid, and taurine, as well as impairment in utilization of vitamin B6 derivatives, are reported.

\section{CASE REPORT}

L.E. was a 6-month-old white female admitted to the Pediatric Department at the University of Missouri Medical Center with the chief complaint of progressive irritability, loss of interest in surroundings, general decrease in activity, and loss of appetite of one month's duration.

The patient was described as normal at birth. Pregnancy, delivery, and the neonatal period were said to be uncomplicated. Birth weight was $6 \mathrm{lb} .3 \mathrm{oz} .(3 \cdot 6 \mathrm{~kg})$. She developed normally relative to motor, social, and adaptive milestones until she was 5 months old when the above symptoms began to manifest themselves. The patient would no longer reach out for objects. Her social responses were noted to have decreased progress-

'Supported in part by a grant from USPHS HD-00136 and HD-00370. 'Present address: Departments of Pharmacology and Pediatrics, Neuropharmacology Laboratory, Nebraska Psychiatric Institute, University of Nebraska College of Medicine. Currently on leave of absence at Laboratory of Preclinical Pharmacolcgy, NIMH, St. Elizabeth's Hospital, Washington, D.C.

'Present address: The Central Institute of Cerebral Palsy, Box 3859 Oslo 8, Norway.

'Present address: Pediatric Neurology, University of Nebraska College of Medicine.

'No further information on the siblings or the patient was available at the time of writing this paper. ively with decrease in laughing and crying relative to environmental and interpersonal changes. There was a gradual and progressive loss of head control as well as progressive feeding difficulty.

There are four siblings. Both parents and the first girl born to the family are healthy. The second girl showed a "central nervous system disorder's from birth, associated with measles encephalitis at the age of 2 years and at the present time is institutionalized. A third child, another girl, died at the age of 6 months from infantile subacute necrotizing encephalopathy. Postmortem examination revealed pathology similar to this case. It is the fourth girl who is being reported here. Pregnancies and deliveries of all four children were uneventful.

On admission, weight, height, and head circumference were 'significantly lower than normal'. Lethargy and little or no spontaneous movements were noted; however, the infant responded to light and auditory stimuli. Temperature was normal and there were no signs of neck rigidity or palpable abnormalities of the fontanelle. There was poor head control as well as poor grasp, rooting, and sucking reflexes and the Moro reflex was present and complete. Generalized muscle hypotonicity with brisk and symmetrical deep tendon reflexes were noted.

LABORATORY STUDIES Electroencephalogram showed diffuse slowing more marked on the left side. Electrocardiogram, electromyogram, and radiographs of the chest and skull were normal. The examination of the urine revealed a negative ferric chloride test and no evidence of aminoaciduria, metachromatic substances, or cytomegalic inclusion bodies. CBC, serum electrolytes, bicarbonate, BUN, blood glucose, serum glutamic oxaloacetic transaminase (SGOT) and serum glutamic pyruvic transaminase (SGPT), and Guthrie test revealed no abnormalities. Cerebrospinal fluid contained a slightly elevated lactic acid dehydrogenase of 47.5 BB units (normal 5 to 40 units), but was otherwise normal. Chromosome study revealed no abnormalities. Other studies will be discussed later in this paper.

The disease progressed rapidly. Nystagmus, pale optic discs, and maculae were observed. Reactions to light and sound disappeared. Difficulties in swallowing with accumulation of mucus in the pharynx and episodic choking were problems at this point. Lingual fascicu- 
lations with deviation of the tongue to the right were noted. The muscle hypotonia and deep tendon reflexes increased and periodically bilateral ankle clonus was reported. Babinski reflex was present on the right and there was a normal plantar response on the left.

Death occurred 22 days after admission with progressive apnoea and finally cardiac arrest.

NECROPSY At necropsy, multiple circumscribed areas of necrosis (similar to recent infarcts) were noticed bilaterally in putamen, globus pallidus, and the caudate nucleus. Along the walls of the aqueduct and the third ventricle a continuous dark pinkish area was bilaterally present. Histopathological examination revealed numerous newly formed and proliferating capillaries with varicose dilatation in the focal lesions of the basal ganglia. Astrocytes and microglia heavily infiltrated the area around the third ventricle. No lesions were observed in the optic tracts, cerebellum, spinal cord, or mammillary bodies. No deposition of lipids could be detected.

The necropsy report on the patient's sister, together with preserved brain slides, were reviewed and compared. Both localization and type of lesions seemed strikingly similar in the two cases. Therefore, the diagnosis of infantile subacute necrotizing encephalopathy (ISNE) was confirmed by the necropsy reports.

RATIONALE FOR STUDYING AMINES AND COENZYME B6 In normal children, the serotonin level (Hazra, Benson, and Sandler, 1965; Mitchell, and Cass, 1959) and the urinary excretion of 5-hydroxyindoleacetic acid (Serra, 1958; Rappallini and Murtagh, 1962) approach adult values between 6 weeks and 4 months of age.

The complete absence of urinary 5-hydroxyindoleacetic acid (adult normal value 2 to $9 \mathrm{mg} / 24 \mathrm{hr}$ ) suggested a possible abnormality in the amine metabolism in this patient. Since the common denominator of this disorder is a necrotizing process in the brain-stem, it was decided to study the biogenic amines which play a decisive role in the maintenance of integrity of the extrapyramidal motor system in the brain. Any other biochemical studies conducted were consequential and explorative in nature and were carried out to delineate further the abnormalities found.

When a lack of 5-HIAA was discovered in the randomly collected urine, an attempt was made to study this metabolite more carefully. Therefore, two 24-hour urine samples were collected from the patient and a child of similar age and weight, who was hospitalized for a routine non-neurological condition, served as her control. The urine was frozen at $-20^{\circ} \mathrm{C}$, without addition of any preservative, immediately after it was voided. The negligible concentration of 5-HIAA in the 24-hour urine sample confirmed the previous findings of the clinical laboratory.

Since the enzymes which synthesize serotonin, dopamine, and gamma-amino butyric acid are B6 dependent (Holtz and Palm, 1964), it was decided to examine the two systems extensively. At necropsy, a portion of the basal ganglia was removed for histopathological examination as well as for the estimation of the concentration of the amines and determination of the activities of certain key enzyme systems. The basal ganglia of two children who died from bacterial endocarditis and Wilm's tumour respectively served as control. The necropsy material, as well as histological examination of the brain tissue, revealed no detectable pathology in the latter children. Because of our previous knowledge that the patient's sister was affected with ISNE as well as the fact that brain amine concentration will decrease upon storage, the brain was removed within 30 minutes after death.

\section{MATERIALS AND METHODS}

Urinary 4-pyridoxic acid, xanthurenic acid, taurine, dopamine, and 5-hydroxyindoleacetic acid were determined according to the methods of Reddy, Reynolds, and Price (1958); Satoh and Price (1958); Hope (1957); Carlsson and Waldeck (1958); and Udenfriend, Weissbach, and Brodie (1958) respectively. The brain dopamine, noradrenaline, and serotonin were determined according to the method of Fleming, Clark, Fenster, and Towne (1965), while the concentration of tryptamine was determined utilizing the method of Eccleston, Ashcroft, Crawford, and Loose (1966). The activity of brain glutamic acid decarboxylase and pyridoxal phosphokinase were estimated according to the methods of Lowe, Robins, and Eyerman (1958), and McCormick, Gregory, and Snell (1961) respectively. The concentration ob the amines and the activity of the enzymes were calcu禺 lated on the basis of dry brain weight.

\section{RESULTS}

The biochemical abnormalities which were found in the urine as well as in the basal ganglia are sumo marized in Tables I and II respectively. There occurred an increase in the 24-hour excretion of 4-pyridoxic acid, as well as xanthurenic acid, while the concentration of taurine became depressed. Among the biogenic amine metabolites, the concentration of 5-hydroxyindoleacetic acid was almost undetectable, while a copious quantity of dopamine was discovered in the urine. Among the biogenic amines and enzymes measured in the basal ganglia, the concentrations of dopamine, noradrenaline, and serotonin and the activity of glumatic acid

TABLE I

ABNORMAL EXCRETION OF BIOGENIC AMINES AND VITAMIN B6 METABOLITES IN THE URINE OF THE PATIENT WITH ISNE

\begin{tabular}{lcc}
\hline & $\begin{array}{c}\text { Patient with } \\
\text { ISNE }\end{array}$ & $\begin{array}{c}\text { Normal } \\
\text { child }\end{array}$ \\
\hline 4-Pyridoxic acid $(\mu \mathrm{M} / 24 \mathrm{hr})$ & 12.80 & 1.85 \\
Xanthurenic acid $(\mu \mathrm{M} / 24 \mathrm{hr})$ & 3.20 & 0.750 \\
Taurine $(\mathrm{mg} / 24 \mathrm{hr})$ & 0.70 & 12.8 \\
Dopamine $(\mathrm{mg} / 24 \mathrm{hr})$ & 20.8 & 0.15 \\
5-Hydroxyindoleacetic acid (5-HIAA) & $<0.1$ & 4.0 \\
(mg/24 hr) & $<$ \\
\hline
\end{tabular}

*No-tryptophan load was given. 
TABLE II

DERANGEMENT IN THE CONCENTRATION OF BIOGENIC AMINES AND IN THE ACTIVITY OF CERTAIN B6 RELATED ENZYMES IN THE BASAL GANGLIA OF THE PATIENT WITH ISNE*

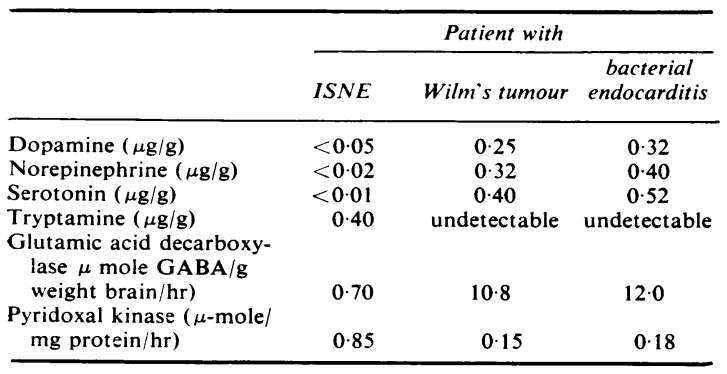

* The concentration of amines and the activity of the enzymes are expressed on the basis of dry weight of the brain.

decarboxylase were depressed, while the concentration of tryptamine and the activity of pyridoxal kinase were significantly increased.

\section{DISCUSSION}

The experimental evidence indicates that in this patient the metabolism of vitamin B6 and biogenic amines were altered. The elevated level of xanthurenic acid along with the reduced level of taurine are suggestive of a generalized state of vitamin B6 deficiency. This suggestion is strengthened by the fact that the activities of cysteine sulfinic acid decarboxylase (as evidenced by low taurine excretion) and glutamic acid decarboxylase (as evidenced by a direct measurement in the basal ganglia), which require pyridoxal phosphate (PLP) as their coenzyme, were depressed. Although the biochemical data are indicative of tissue vitamin B6 deficiency, the excretion of 4-pyridoxic acid, the end-product of vitamin B6, became elevated several-fold. It is also of interest that the activities of SGOT and SGPT, the B6-requiring enzymes, were normal. Cox, Murray, and Boone (1962), while studying tritium-labelled pyridoxine, found that the major portion of pyridoxine is excreted unchanged, $17 \%$ is stored in the tissue to be utilized for future coenzymatic activity, and less than $2 \%$ is enzymatically metabolized to 4-pyridoxic acid which is excreted in the urine. The elevated 4-pyridoxic acid excretion in the urine could result from (1) pyridoxine injection or (2) lack of storage of the compound in the tissue which is subsequently subjected to catabolism. In the case of our patient, no pyridoxine was administered. The presence of depressed activity of cysteine sulfinic acid decarboxylase, which is found in most peripheral organs
(Blaschko, 1942; and Blaschko, Carter, O'Brien, and Stanley, 1948); and of glutamic acid decarboxylase, which is predominantly in the central nervous system (Vates, Agranoff, and Sokoloff, 1959), suggests that a state of impairment in B6 utilization existed in the presence of an adequate intake of vitamin in the diet. The evidence for a tissue depletion of vitamin B6 was strengthened by the observation that the activity of pyridoxal kinase, an enzyme which converts pyridoxal, pyridoxamine, and pyridoxine to their phosphorylated forms, was elevated several-fold in the basal ganglia. This postulate is in keeping with the observation of Ebadi and McCoy (1966) and Ebadi, Russell, and McCoy (1968) that the tissue level of vitamin B6 and biogenic amines influence the activity of pyridoxal kinase in brain.

In mammalian tissues the available dopamine is formed from dopa by the aid of a PLP-dependent enzyme, dopa decarboxylase (Lovenberg, Weissbach, and Udenfriend, 1962). The dopamine is then hydroxylated by dopamine $\beta$-hydroxylase to yield noradrenaline (Udenfriend and Creveling, 1959) and is oxidatively deaminated to form 3,4-dihydroxyphenylacetic acid, and the latter compound becomes o-methylated to produce homovanillic acid (Carlsson and Hillarp, 1962; Andén, Roos, and Werdinius, 1963) (Fig. 1). In this patient the concentration of dopamine and noradrenaline in the basal ganglia were extremely low (Table II). These low concentrations of the two amines could be caused by the depressed activity of dopa decarboxylase (which is a PLPdependent enzyme) resulting in inadequate formation of dopamine and of course, indirectly, noradrenaline. Although the basal ganglia contained very little dopamine, the urinary excretion of dopamine was high. These inconsistencies are very difficult to explain. Assuming that the low concentration of dopamine in the basal ganglia resulted from a depression in the activity of dopa decarboxylase, then why were similar enzymes not inhibited in the peripheral systems?

The findings can be explained only if one postulates that the activity of tyrosine hydroxylase and/or dopa decarboxylase in the brain and monoamine oxidase in the peripheral tissues were selectively inhibited (Fig. 1). Because of an insufficient amount of experimental evidence, further description of this complex mechanism will not be undertaken.

The serotonin content of the basal ganglia was quantitatively negligible. This low concentration of serotonin in the brain is, however, in keeping with the extremely low excretion of 5-hydroxyindoleacetic acid in the urine (Table I).

The existing serotonin in the body is formed from decarboxylation of 5-hydroxytryptophan by 


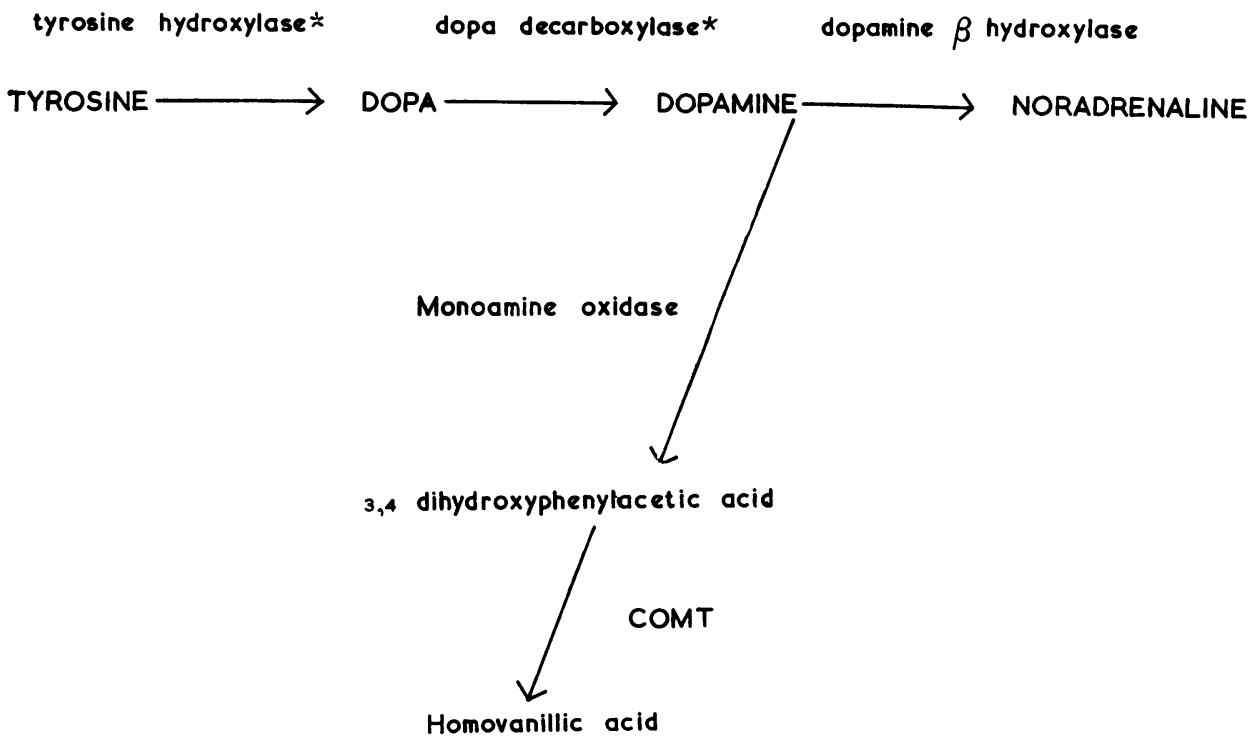

FIG. 1. Biochemical pathways leading to formation and degradation of dopamine. The possible enzymatic inactivation in the patient's brain is designated in two reactions by single asterisks.

the aid of a PLP-dependent 5-hydroxytryptophan decarboxylase (Lovenberg et al., 1962). The 5hydroxytryptophan is produced by direct hydroxylation of tryptophan under the catalytic action of tryptophan hydroxylase. Tryptophan can also be directly decarboxylated, by tryptophan decarboxylase, to yield tryptamine (Werle and Mennicken, 1937). Serotonin and tryptamine are oxidatively deaminated to yield 5-hydroxyindoleacetic acid which is excreted in concentrations of 2 to $9 \mathrm{mg} / 24 \mathrm{hr}$, and indoleacetic acid which is excreted in con- centrations of 5 to $18 \mathrm{mg} / 24 \mathrm{hr}$ (Jackson an $\$$ Chandler, 1939; and Weissbach, King, Sjoerd ${ }^{\circ}$ sma, and Udenfriend, 1959) (Fig. 2). Although the concentration of serotonin in the basal ganglia is approximately $0.5 \mu \mathrm{g} / \mathrm{g}$ wet brain tissue, the cor centration of tryptamine is negligible, since it is very rapidly oxidized to indoleacetic acid whic is excreted in the urine. It is rather interesting that in this patient, in the absence of serotonin, the concentration of tryptamine became elevated (Table II). There is little doubt that the build-up of this

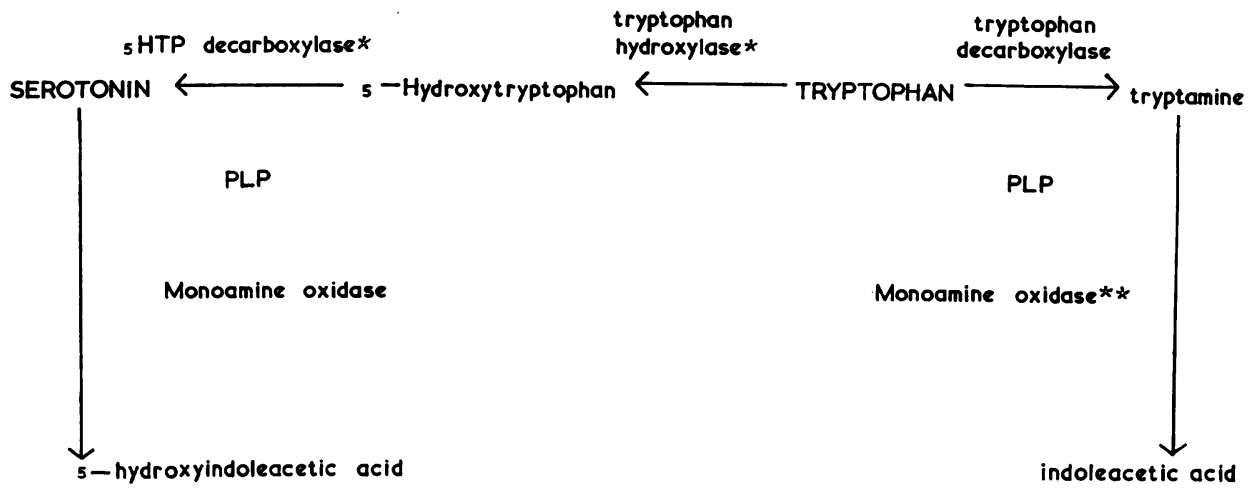

FIG. 2. Biochemical pathways leading to formation and degradation of serotonin and tryptamine. The postulated enzymatic inactivation which led to decreased concentration of serotonin and increased concentration of tryptamine in the patient with ISNE are designated by a single asterisk and a double asterisk respectively. 
amine is due to inhibition of the activity of monoamine oxidase. The depressed concentration of serotonin in the brain, along with decreased excretion of 5-hydroxyindoleacetic acid in the urine, is clearly suggestive of inadequate synthesis of serotonin, which results from an inhibition of tryptophan hydroxylase and/or 5-hydroxytryptophan decarboxylase.

It is extremely difficult to understand the relation between the disease subacute necrotizing encephalopathy and the biochemical abnormalities detected. For example, it is not known to what extent, if any, the discussed biochemical abnormalities contribute to the onset and pathological characteristic of the disease, nor is it clear to what degree these derangements are manifestations of the disease state with a far more complicated cause and aetiology. However, it is unlikely that the degenerative processes in the brain-stem would have been arrested, even if one had the capability of biochemically correcting the reported B6 and amine abnormalities. Furthermore, it is conceivable that these multiple enzymatic blockades, as reported in this paper and other studies (Greenhouse and Schneck 1968; Namiki, 1965; and Worsley et al., 1965), are the results of non-specific action of a substance or substances elaborated by the disease, capable of creating a massive breakdown in decarboxylating mechanisms everywhere. The evidence presented in this report indicates that the inhibition in decarboxylating systems might be due to impairment in catalytic utilization of vitamin B6 derivatives.

\section{SUMMARY}

This paper reports the biochemical abnormalities found in the basal ganglia and the urine of a child with subacute necrotizing encephalopathy. The urinary levels of 4-pyridoxic acid, xanthurenic acid, and dopamine were elevated, whereas the levels of taurine and 5-hydroxyindoleacetic acid were depressed. The basal ganglia levels of dopamine, noradrenaline, serotonin, and the activity of the glutamic acid decarboxylase were depressed, whereas the level of tryptamine and the activity of pyridoxal kinase were elevated. These data are interpreted to indicate that in this child there occurred an impairment in utilization of vitamin B6 and in amino acid decarboxylating systems.

The authors wish to express their gratitude to Dr. Victor Lopez and the Department of Pathology of the University of Missouri School of Medicine for providing the necropsy materials as well as histopathological information about the brains of the children studied.

\section{REFERENCES}

Andén, N. E., Roos, B. E., and Werdinius, B. (1963). On the occurrence of homovanillic acid in brain and cerebrospinal fluid and its determination by a fluorometric method. Life Sci., 2, 448-458.

Blaschko, H. (1942). I(-)-cysteic acid decarboxylase. Biochem. J., 36, $571-574$

Carter, C. W., O'Brien, J. R. P., and Stanley, G. H. S. (1948). Pyridoxin in relation to amine formation in the mammalian liver. J. Physiol. (Lond.), 107, 18P-19P.

Carlsson, A., and Hillarp, N-A. (1962). Formation of phenolic acids in brain after administration of 3,4 dihvdroxyphenylalanine. Acta physiol. scand., 55, 95-100.

- and Waldeck, B. (1958). A fluorimetric method for the determination of dopamine (3-hydroxytyramine). Ibid., 44, 293-298.

Cox, S. H., Murray, A., and Boone, I. U. (1962). Metabolism of tritium-labeled pyridoxine in rats. Proc. Soc. exp. Biol. (N.Y.), 109, 242-244.

Crome, L. (1964). Neuropathological changes in diseases caused by inborn errors of metabolism, pp. 31-51, in Neurometabolic Disorders in Childhood: Proceedings of a Symposium. Edited hy K.S. Holt and J. Milner. Livingstone: Edinburgh.

Ebadi, M. S., and McCoy, E. E. (1966). The effect of neuropharmacological agents on the activity of pyridoxal phosphokinase in rabbit's brain. Fed. Proc., 25, 560.

, Russell, R. L., and McCoy, E. E. (1968). The inverse relationship between the activity of pyridoxal kinase and the level of biogenic amines in rabbit brain. J. Neurochem., 15, 659-665.

Eccleston, D., Ashcroft, G. W., Crawford, T. B. B., and Loose, R. (1966). Some observations on the estimation of tryptamine in tissues. Ibid., 13, 93-101.

Feigin, I., and Wolf, A. (1954). A disease in infants resembling chronic Wernicke's encephalopathy. J. Pediat., 45, 243-263.

Fleming. R. M., Clark, W. G., Fenster, E. D., and Towne, J. C. (1965). Single extraction method for the simultaneous fluorometric determination of serotonin, dopamine, and norepinephrine in brain. Anal. Chem., 37, 692-696.

Greenhouse, A. H., and Schneck, S. A. (1968). Subacute necrotizing encephalomyelopathy. A reappraisal of the thiamine deficiency hypothesis. Neurology (Minneap.), 18, 1-8, 46

Hazra, M., Benson, S., and Sandler, M. (1965). Blood 5-hydroxytryptamine levels in the newborn. Arch. Dis. Childh., 40, 513-515.

Holtz, P., and Palm, D. (1964). Pharmacological aspects of vitamin B6. Pharmacol. Rev., 16, 113-178.

Hope, D. B. (1957). The persistence of taurine in the brains of pyridoxine deficient rats. J. Neurochem., 1, 364-369.

Jackson, R. W., and Chandler, J. P. (1939). Metabolism of proteins and amino acids. Ann. Rev. Biochem., 8, 249-268.

Leigh, D. (1951). Subacute necrotizing encephalomyelopathy in an infant.J. Neurol. Neurosurg. Psychiat., 14, 216-221.

Lovenberg, W., Weissbach, H., and Udenfriend, S. (1962). Aromatic L-amino acid decarboxylase. J. biol. Chem., 237, 89-93.

Lowe, I. P., Robins, E., and Eyerman, G. S. (1958). The fluorimetric measurement of glutamic decarboxylase and its distribution in brain. J. Neurochem., 3, 8-18.

McCormick, D. B., Gregory, M. E., and Snell, E. E. (1961). Pyridoxal phosphokinases: I. Assay, distribution, purification, and properties. J. Biol. Chem., 236, 2076-2084.

Mitchell, R. G., and Cass, R. (1959). Histamine and 5-hydroxytryptamine in the blood of infants and children. J. clin. Invest., $38,595-604$.

Namiki, H. (1965). Subacute necrotizing encephalomyelopathy: Case report with special emphasis on associated pathology of peripheral nervous system. Arch. Neurol. (Chic.), 12 98-107.

Rappallini, C., and Murtagh, J. J. (1962). La serotonina y el acido 5-hidroxindolacetico en el recien nacido. Sem. med. (B. Aires), 121, 1239-1250.

Reddy, S. K., Reynolds, M. S., and Price, J. M. (1958). The determination of 4-pyridoxic acid in human urine. J. biol. Chem., 233, 691-696.

Richter, R. B. (1957). Infantile subacute necrotizing encephalopathy with predilection for the brain stem.J. Neuropath. exp. Neurol., 16, 281-307.

Satoh, K., and Price, J. M. (1958). Fluorometric determination of kynurenic acid and xanthurenic acid in human urine. J. biol. Chem., 230, 781-789. 
Serra, U. (1958). L'eliminazione urinaria dell' acido 5-idroxyindolacetico in bambini normali. Fd. Endocv. (Roma), 11, 410-417. Udenfriend, S., and Creveling, C. R. (1959). Localization of dopamine- $\beta$-oxidase in brain. J. Neurochem., 4, 350-352.

—- Weissbach, H., and Brodie, B. B. (1958). Assay of serotonin and related metabolites, enzymes and drugs. Meth. biochem. Anal., 6, 95-130.

Vates, T., Agranoff, B., and Sokoloff, L. (1959). Glutamic decarboxylase activity in human cerebrospinal fluid. Fed. Proc., 18, 164.
Weissbach, H., King, W., Sjoerdsma, A., and Udenfriend, S. (1959). Formation of indole-3-acetic acid and tryptamine in animals: A method for estimation of indole-3-acetic acid in tissues. J. biol. Chem., 234, 81-86.

Werle, E., and Mennicken, G. (1937). Uber die Bildung von Tryptamin aus tryptophan und von Tyramin aus Tyrosin durch tierisches Gewebe. Biochem. Z., 291, 325-327.

Worsley, H. E., Brookfield, R. W., Elwood, J. S., Noble, R. L., and Taylor, W. H. (1965). Lactic acidosis with necrotizing encephalopathy in two sibs. Arch. Dis. Childh., 40, 492-501. 